\title{
The Use of Mixed Methods to Study Greek and Turkish Cypriot University Students' Attitudes towards the 'Other'
}

\author{
Andri Neophytou \\ Department of Sociology, University of Eastern Finland, Finland
}

Copyright@2019 by authors, all rights reserved. Authors agree that this article remains permanently open access under the terms of the Creative Commons Attribution License 4.0 International License

\begin{abstract}
The aim of the current article is to discuss the importance of using mixed methods in social sciences research, by referring to Neophytou [1] methodology and results. Neophytou [1], using qualitative and quantitative research methods in the same research, arguably provided a general picture of the attitudes of Greek and Turkish Cypriot university students towards each other. The results of the quantitative research informed the development of the qualitative research. Some of the results confirmed those of previous research, whereas others where new and noteworthy. For example, the quantitative research revealed that attitudes towards the 'Other' and proximity with the 'Other' are positively correlated, something that was seen in previous research. Additionally, in both cases, Greek and Turkish Cypriot participants were more positive towards their in-groups over their out-groups, but surprisingly, Turkish Cypriots appeared less negative towards their out-group compared with Greek Cypriots. Students' concern about language and religion were obvious, though this was expressed mainly by Greek Cypriots. Turkish Cypriots appeared more eager to meet other cultures (East and West); they had heard, read and lived other cultures more than Greek Cypriot participants. The above and other findings raised new questions that were further analysed with the use of qualitative methods. The proper use of mixed methods gave a holistic view of Greek and Turkish Cypriots conceptions and misconceptions towards the 'Other Cypriot'.
\end{abstract}

Keywords Qualitative, Quantitative, Mixed Methods, Greek, Turkish, Cypriots, Otherness

\section{Introduction}

Sociology researchers are often concerned about the use of qualitative or quantitative methods. However, mixed research methods can be an appropriate option. Each method should be used according to the desirable knowledge to be produced. This article discusses a successful example of using mixed methods (qualitative and quantitative methods in the same study) in sociological research. This research used mixed methods to study attitudes of Greek and Turkish Cypriot students towards the 'Other' [1].

Cyprus is a small island in the Mediterranean Sea at the juncture of three continents (Europe, Asia and Africa), and it was quite often seen in conflict situations throughout the centuries. Conducting sociological studies about Cyprus is a challenge for sociology researchers, primarily because of a call for co-existence between its Greek and Turkish Cypriot inhabitants since 1500 a. C. Studying the attitude of Greek and Turkish Cypriot university students towards the Other was seen as part of a larger problem concerning the in-group and inter-group relations of the two communities throughout history. Greek and Turkish Cypriots are culturally diverse in terms of language and religion. However, they also have cultural similarities, mainly because of their extensive historical presence on the island.

The main aim of this research was to explore the attitudes of Greek and Turkish Cypriot university students towards the Other Cypriot (the 'Other' for Greek Cypriots is the Turkish Cypriot community and the 'Other' for Turkish Cypriots is the Greek Cypriot community) and the possible reasons behind their attitudes. Attitudes can be positive, negative or neutral [1]. The research further aimed to provide an insight into students' conceptions and misconceptions of their in-group (Greek Cypriots towards Greek Cypriots and Turkish Cypriots towards Turkish Cypriots) in comparison to their out-group (Greek Cypriots towards Turkish Cypriots and Turkish Cypriots towards Greek Cypriots). The aims were developed by considering two dimensions: the background (historical, social and political) and the theories/approaches related to the 'sense 
of nationalism'(that is related-among others- to the students' sense of identity, conceptions about language and religion), 'contact with other cultures' (this variable examines students' contact with other cultures- what they read/heard/ experienced about eastern/western cultures) and 'proximity/involvement with the "Other"' (this variable studies what the students read/heard/ experienced about the "other Cypriot”). The researcher used qualitative and quantitative methods in a way that both methods were considered equally important and necessary.

\section{Materials and Methods}

This study used qualitative methods that were conducted after quantitative methods, but one research method was no less important or less significant than the other. The two methods were interconnected. Other research examples that used mixed methods have been described by Black [2, 3], Bryman [4], Miles and Huberman [5] and Newman and Benz [6] and others. The methodology was based on the research plan presented in Figure 1.

The research began with observation of world events, and more specifically of the Cypriot reality. These observations were generalised through induction, and some hypotheses were developed. The initial hypotheses of the research are presented below:

1. There is a positive correlation between the construction of one's sense of nationalism and one's attitude towards the 'Other'.
2. There is a positive correlation between student's contact with other cultures and their attitude towards the 'Other'

3. There is a positive correlation between proximity/involvement with the 'Other' and the attitude towards the 'Other'.

4. Greek Cypriot university students have a very negative attitude towards Turkish Cypriots.

5. Turkish Cypriot university students have a very negative attitude towards Greek Cypriots.

6. Both groups have a very positive attitude towards their in-group.

7. Students coming from a refugee family (after 1974) have a more negative attitude towards the 'Other'

The hypotheses or the 'new theory' needed to be explained by deduction. The tendencies of groups of people and relations between specific variables needed to be described. Through quantitative research (SPSS analysis), relations were discovered and described. Through qualitative research (written documentary analysis, presentation and analysis of previous research, newspaper articles, seminar results, historical and contemporary reports, newspaper interviews, government addresses and proceedings) new hypotheses appeared and certain limitations on explanations were set. This research plan was influenced by Black's ideas [2]. As soon as the results were generated, a need for further research and analysis was revealed. For this reason, a list of possible explanations/ new hypotheses was created as a second instrument aside from the questionnaire, which was the first instrument.

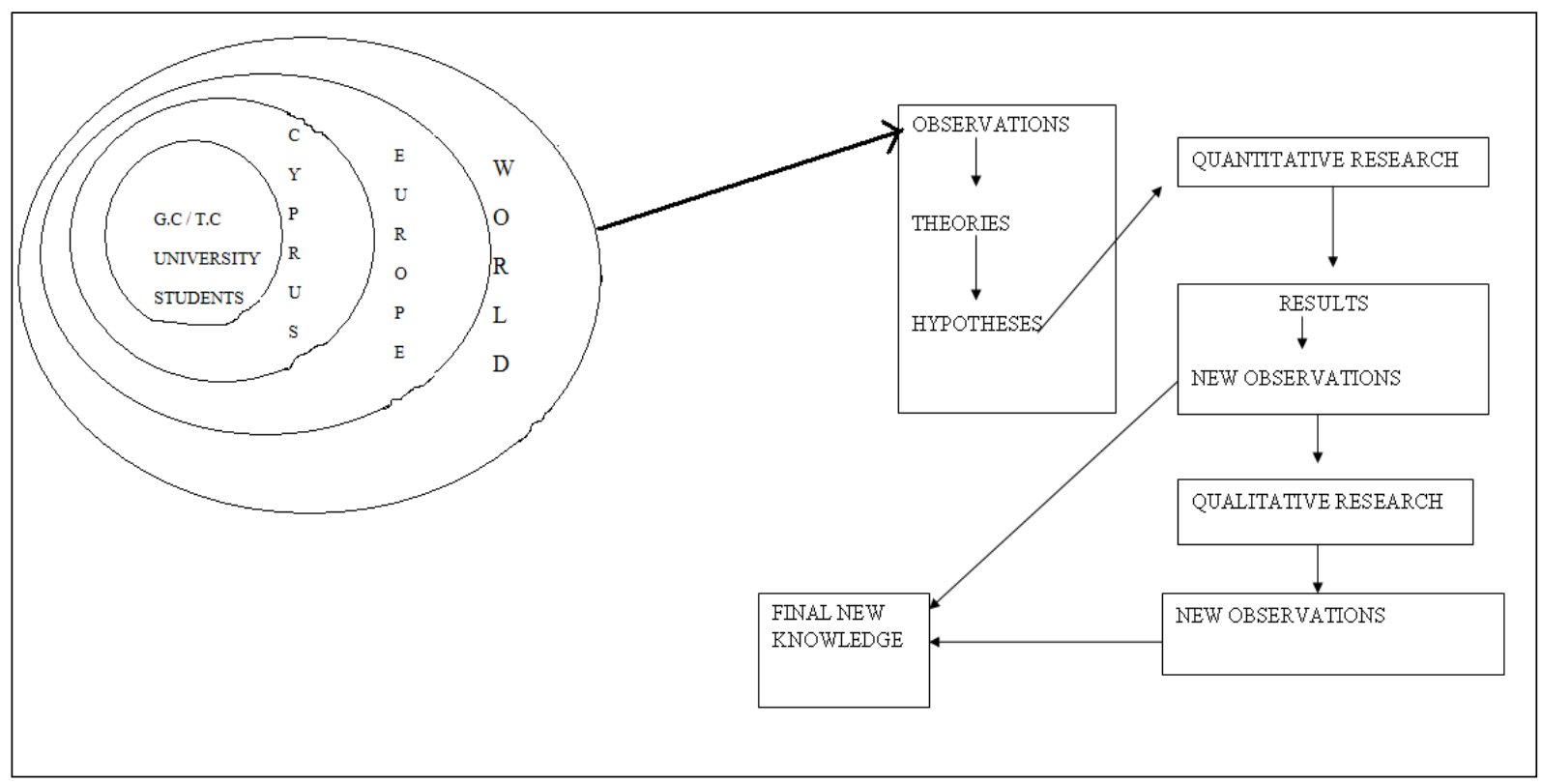

Figure 1. Research plan. (Neophytou, 2014) 
The new hypotheses are presented below:

- Greek Cypriot students' more negative attitude towards the 'Other' is related to their stronger feelings concerning their sense of victimisation.

- Although Turkish Cypriots try to become more independent from Turkey, Greek Cypriots do not distinguish Turkish Cypriots and Turkish policy (distinction of special identities) on Cyprus (which explains their negative attitude towards the 'Other').

\subsection{Historical and Theoretical Background}

As it was previously mentioned, Neophytou [1] began her study based on two dimensions, the historical and the theoretical backgrounds. Both are described in the following lines.

\subsubsection{Historical Background}

There are many different perspectives describing the history of Cyprus. To the authors' concern, there is no such thing as a 'history of Cyprus'; in reality, there are many 'histories of Cyprus'( the perspective of the Greek Cypriot, the Turkish Cypriot, the Greek Cypriot centre, left or right, the Turkish Cypriot centre, left or right, the perspectives of foreign countries (e.g., the British perspective), the perspectives of the upper or lower social classes). Neophytou [1] attempted to provide the dominant understandings and interpretations of Cyprus' history and to provide the best possible realistic portrait.

Cyprus has a long history dating 5,800 years. The first inhabitants probably came from the Balkans, Cilicia or Macedonia. Inhabitants from Greece settled on the island around 2000 B.C. The then Cypriot inhabitants adopted the Greek language, religion and customs. Despite the fact that throughout the centuries, there were different administrative arrangements and/or other situations (e.g., wars/attacks) whereby different peoples ruled the island (e.g., the Mycenaean, Phoenicians, Assyrians, Egyptians, Persians, Macedonians, Romans, Byzantines, Franco-English, Franks, Venetians and others), the population remained intrinsically Greek. The 'Greek-ness' of the island is one of the main primordial arguments in the Greek Cypriot/Greek nationalistic discourse which claims that Cyprus has its roots in ancient Greek history. The Turkish or Turkish Cypriot nationalistic discourse, on the other hand, maintains the 'Turkish-ness' of Cyprus and supports that in ancient years, Cyprus was part of Turkey, but that it was enveloped by the sea.

The Ottoman period (when Ottomant-Turks conquered the island) began in 1571 and lasted until 1878. Inhabitants of the island were divided under the names "Christians" and "Muslims", whereas the 'Cypriot identity' did not exist. The Greek or Turkish identities were not so popular.

The British period followed from 1878 until 1960. Greek and Turkish Cypriots were under the leadership of the British High Commissioner. Greek and Turkish Cypriots met each other in the streets, lived in mixed villages, worked together, but there were no official policies that brought them together (e.g., they studied in different schools). The attitude of the British politicians on the island at the time was based on their widespread colonial policy of "divide and rule" and the members of the two communities did not react to that particular British policy. This divisive attitude was extended to other facets of the society. There was a constant attachment to the motherlands, Greece and Turkey. During this period, there were episodes, sometimes violent, from both sides that empowered the extreme nationalist rhetoric. In 1955, a new ethnic struggle began for Greek Cypriots with the establishment of the EOKA A'. ${ }^{1}$ EOKA A' was a paramilitary nationalist organisation that aimed to put an end to British rule in Cyprus and unite Cyprus with Greece. The establishment of EOKA was followed by that of TMT ${ }^{2}$ in 1957. The Turkish Cypriot side argued that this action was a response to the EOKA struggle that caused fear among them, but TMT actions in the years that followed showed that its members struggled for the partition of the island. After the EOKA struggle, and as world conditions became favourable (many British colonies became independent during this period), the island received its independence from the British in 1960. In 1960, Cyprus became independent, but from then until 1974, it has been characterised as a period of unrest, internal ethnic conflicts. From 1974 to the present, the Line ${ }^{3}$ has divided the two communities (Turkish Cypriots in the North and Greek Cypriots in the South), and as a result, they have autonomous administrations. The Greek Cypriot government is internationally recognised, though not by Turkey, whereas the Turkish Cypriot administration, ${ }^{4}$ the TNRC $^{5}$, is recognised only by Turkey. The Cypriot question has remained unresolved since. A quick glance at the historical line raises many questions about the national identities of Cypriots, the subject of the following sub-section.

Overall, concerning the identity of Cypriots, there are three main discourses on the Greek Cypriot side, 'Hellenocentrism' (the emphasis is on the 'Greek-ness' of Cyprus), 'Cypriocentrism' (the emphasis is on the Cypriot identity) and lastly, 'Hellenocypriocentrism' (inhabitants recognise their link to ancient Greek roots, but see Cyprus as an independent state). Respectively, three or four discourses on identity ('Turkishcentrism',

1 EOKA A': /Ethinki Organosi Kyprion Agoniston/ is the same as the National Organisation of Cypriot Struggle. The 'Cypriot' included only Greek Cypriots. Later on, in 1974 another EOKA was established, called EOKA B', as is later explained.

2 TMT stands for Turkish Resistance Organization. It was a Turkish Cypriot paramilitary organisation that was formed by Rauf Denktash and the Turkish Military as a response to EOKA in 1957. It was very active until 1974.

3 The Line is also called the Green Line or cease-fire line, or border etc. 4 The word 'administration' is used instead of government because the Turkish Republic of Northern Cyprus is a non-recognised state.

5 TRNC stands for Turkish Republic of Northern Cyprus. 
'Cypriotcentrism' 'Turkish Cypriotcentrism' and others) could be recognised among Turkish Cypriots.

At the time of Neophytou research the political, cultural and social framework, appeared to be different (more positive), in a way, from that of the historical situation [1]. Admittedly, there had been some progress in the political, social and economic realms, which could have an impact on people's attitudes. Bearing in mind all of the above, it appeared to be of great importance to uncover the ideas and conceptions of Greek and Turkish university students about history, identity and 'us and them' constructions. Admittedly, there was a research gap, as several researchers ${ }^{6}$ deal with similar issues in the Cypriot context, but none studies the attitudes of the age group in question. Researches on the Cypriot question mainly focus on educational matters, like the content of history or religious books, the need for curricula revision and the conceptions of educators. Additionally, there have been studies on general attitudes of middle-aged people towards the 'Other'. In most of the cases, research refers either to Greek Cypriots or to Turkish Cypriots. In attempting to explore different opinions about the stereotypes, attitudes, identity formation and sense of belonging of Greek and Turkish Cypriots, one can realise that there are different and even contradictory ideas. Additionally, the age group of university students is admittedly difficult, and only very few studies have concentrated on this group. There was a research gap, since there was no study that concerned the attitudes of Turkish and Greek Cypriot university students towards the 'Other'. The present work can help us understand what or how a segment of the population thinks and the methodology and results can be easily replicated in similar research.

\subsubsection{Theoretical Background}

One of the main aims of this study was to examine the attitudes of Greek and Turkish Cypriot university students towards the 'Other'. Attitude was studied under the perspective of certain variables such as sense of nationalism, contact with other cultures and proximity with the 'Other'

6 E.g., Bryant, 2004; Canan-Sokullu \& Sozen, 2010; Constantinou \& Papadakis, 2001; Danielidou \& Horvath, 2006; Gregoriou 2006; Hadjipavlou, 2004; Kizılyürek, 2002; Lacher and Kaymak, 2005; Lordos, Kaymak \& Tocci, 2009; Lordos, Kaymak \& Tocci, 2009; Mertan, 2011; Osam \& Ağazade, 2004; Pachoulides, 2007; Papadakis, Peristianis \& Weltz, 2001; Philippou, 2005; Psaltis, Lytras \& Costache 2011; Ramm, 2006; Sitas, Latif \& Loizou, 2007; Stavrinides \& Georgiou, 2011; Vural and Rustemli, 2001; Yilmaz, 2010; Zembylas, Michaelidou and Afantitou, 2010; Zembylas, 2010. 


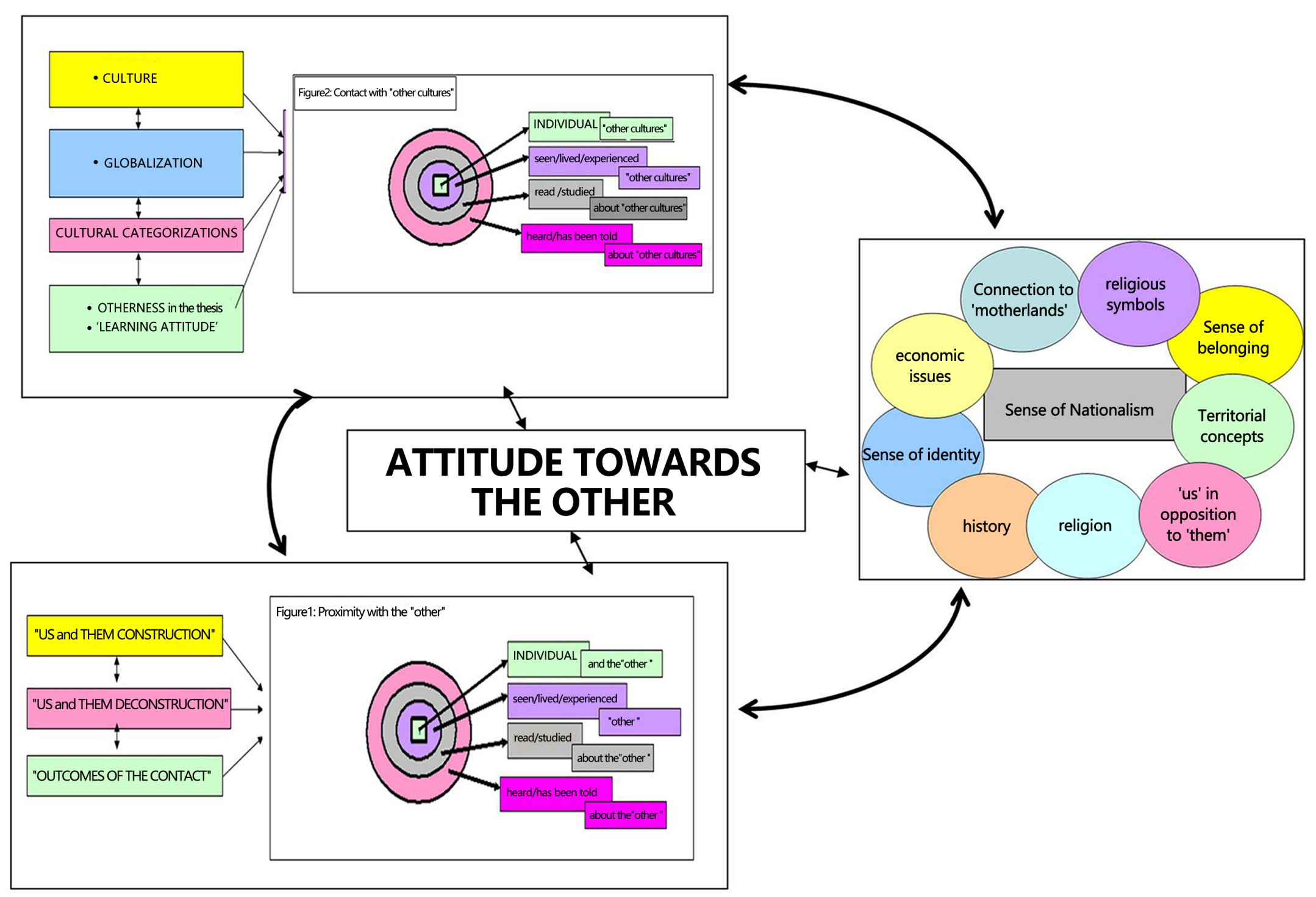

Figure 2. Construction of theories, Neophytou [1] 
In the current research, attitudes are examined by considering the ideas expressed by traditional theories as well as more recent theories. Ideas, conceptions, emotions and possible actions are analysed, but a holistic view of attitude is discussed, which is related to the overall experiences of the students. This approach forms a combination of the $\mathrm{ABC}$ and other recent frameworks. For example, studying students' attitudes towards the 'Other' included questions concerning the eagerness of the participant to learn the language of the 'Other', meeting the 'Other', becoming friends with the 'Other' or students' actions (e.g., participation in bi-communal events, or intercultural events). Cypriot students' attitudes were studied as a whole, taking into consideration feelings, behaviour, actions, and beliefs.

"Proximity with the Other" concerns the level of contact of Greek and Turkish Cypriots with the 'Other'. Several approaches dealing with the discursive issue of identity are very relevant to the questions of this thesis. There are theories (e.g., schema theory, social representation theory, social attribution theory, cognitive dissonance theory, the presented self) that consider identity as developed in a passive way, and consequently, intergroup discrimination remains stable and unchangeable (see Monroe, Hankin \& Van Vechten [22). Contrary to the above, there are theories (e.g., social constructionism) that support the active construction of identity, and therefore, intergroup conflict is contextual and changeable (Monroe et al. [22]). In the thesis, the term 'construction' has a functional role (meaning the creation, or the building of...) and is related to the second approach. In this sense, contact with the 'Other' can exist on various levels. The first concerns what the person has heard, the second, what the person has read, and the third, what the person has seen/lived/experienced (see also Bauman and May [23]). One of the aims of the current study was to explore the relation between attitudes towards the 'Other' with reference to Greek and Turkish Cypriot university students' experiences with the 'Other'. Literature showed that proximity with the 'Other' can correlate with negative or positive attitudes. One question pertains to Cypriot students' conceptions towards 'meeting' the other (on different levels: heard, read, met) and the correlations with their attitude towards the 'Other' because of a lack of research on Cyprus in this area.

The variable named 'Contact with other cultures' in Neophytou [1] study examines whether students have had some form of contact with other cultures, and at what level. Contact can be achieved when travelling abroad, meeting people from other countries, reading about other cultures, listening to other cultures. In order to research the intercultural and interfaith learning of students, contact on a formal (seminars, conferences, media discussions, educational programs, and others) and informal level (international camping sites, informal methods of discussion concerning culture, drama, dancing, sports and other themes) can be examined. Greek and Turkish university students have a lot in common, but they use different languages and have different religions. It would be interesting to understand their conceptions of the religious symbols of the 'Other' (e.g., church or minaret) as well as other languages (European, Asian, and African), despite the fact that they belong to the same high-context societies. Contact with other cultures seems to be an important issue to pursue, as it could be related to the attitude a person holds towards the 'Other'. It was assumed that the ability of Cypriot students to travel abroad, and the flow of different cultures in Cyprus mainly because of immigration, has probably influenced their way of understanding their sense of belonging in relation to 'Others' (see Papastergiadis [24]). Moreover, in Said's [25] words, the "electronic, post-modern world has been a reinforcement of the stereotypes by which the Orient is viewed". Contact can be achieved quite easily, especially in the context of information technology (media, internet, on-line libraries etc.). Therefore, 'otherness' in students' thinking can be constructed either from their personal experiences with people from other countries or from what they have heard or seen on television, in books or newspapers. It was assumed that a learning attitude is constructed in students' minds in a way that personal values are rendered to universal ones. The author considered Gudykunst's [26] theory that the way we act intra-culturally (inside our own culture) is consistent with the way we act inter-culturally (with other cultures). Therefore, contact with other cultures could correlate with proximity with the 'Other' and both of these variables could correlate with attitude towards the 'Other'. Yet, these are just some of the assumptions of the thesis, and as there is a research gap around this issue, these assumptions were further investigated.

The approaches the author studied in order to form the variable ‘sense of nationalism' are presented on Figure 3. 


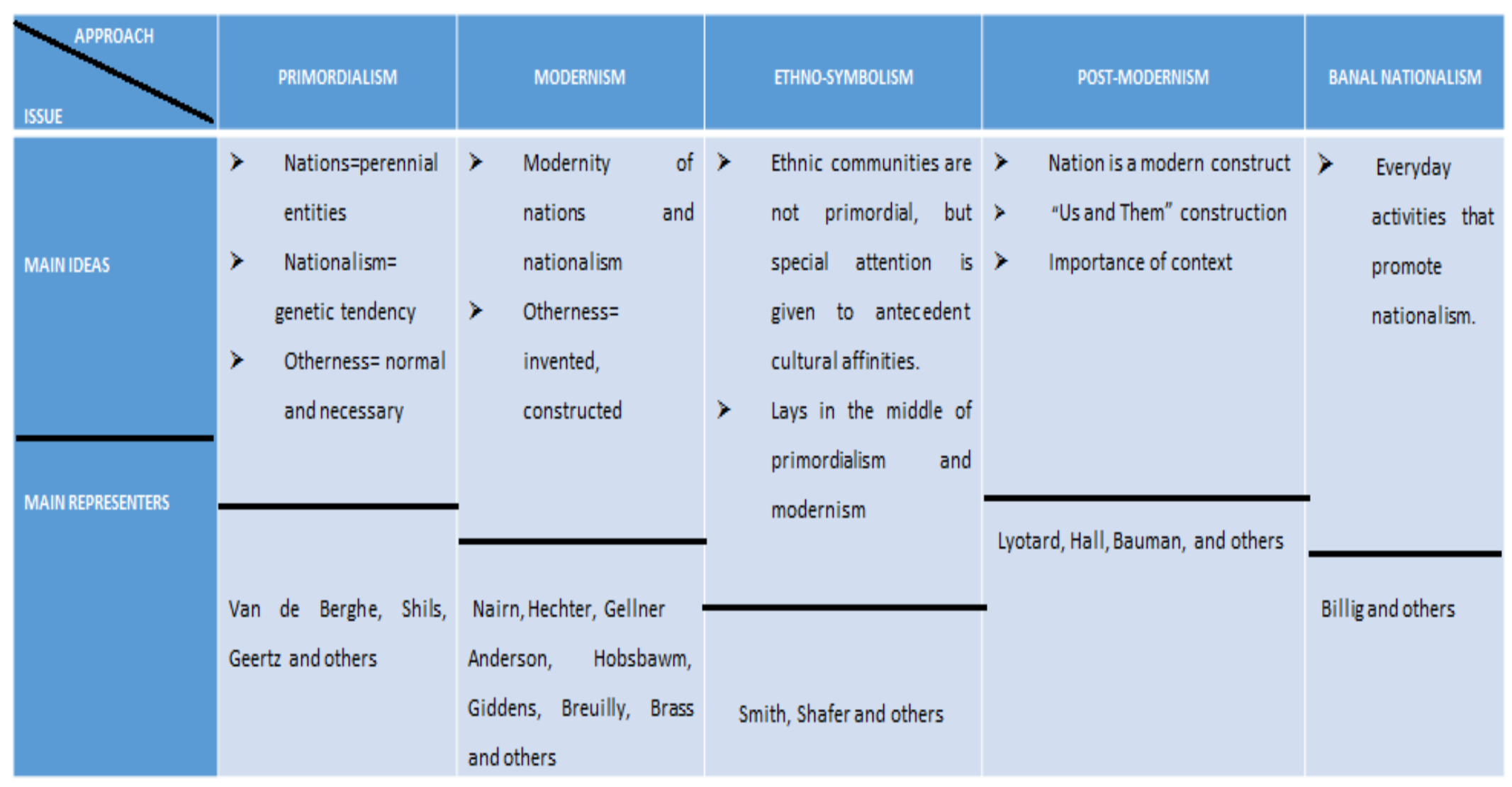

Figure 3. Naionalism 
The theoretical review showed that the following issues are related to the 'sense of nationalism'.

- $\quad$ Sense of identity or sense of belonging (Cypriot, Greek Cypriot, Turkish Cypriot, Turkish, Greek)

- $\quad$ Connection to 'motherlands' - imagined communities

- Conceptions of religion

- Conceptions of history

- Conceptions of economic issues/issues of interest

- Territorial concepts

- Attitude towards symbols (e.g., religious symbols: minaret/church, language)

- Defining 'us' in opposition to 'them'

The author assumed that sense of nationalism could be linked to the students' attitude towards the 'Other', as one of the main aims of nationalism is to emphasise the ethnic differences between 'us' and 'them'. Additionally, it was the assumption of Neophytou thesis that nationalism could relate to proximity with the 'Other'. It was assumed that if a person has a stronger sense of nationalism, he/she will probably be less eager to meet the 'Other', as he/she will feel less comfortable with the national symbols, language or religion of the 'Other'. The same logic holds for contact with other cultures. Students with a stronger sense of nationalism could be less eager to meet other cultures as they could, for example, consider them as inferior compared to their own.

Figure 4 presents the construction of the theoretical framework of Neophytou research that was later on studied by qualitative and quantitative research methods.

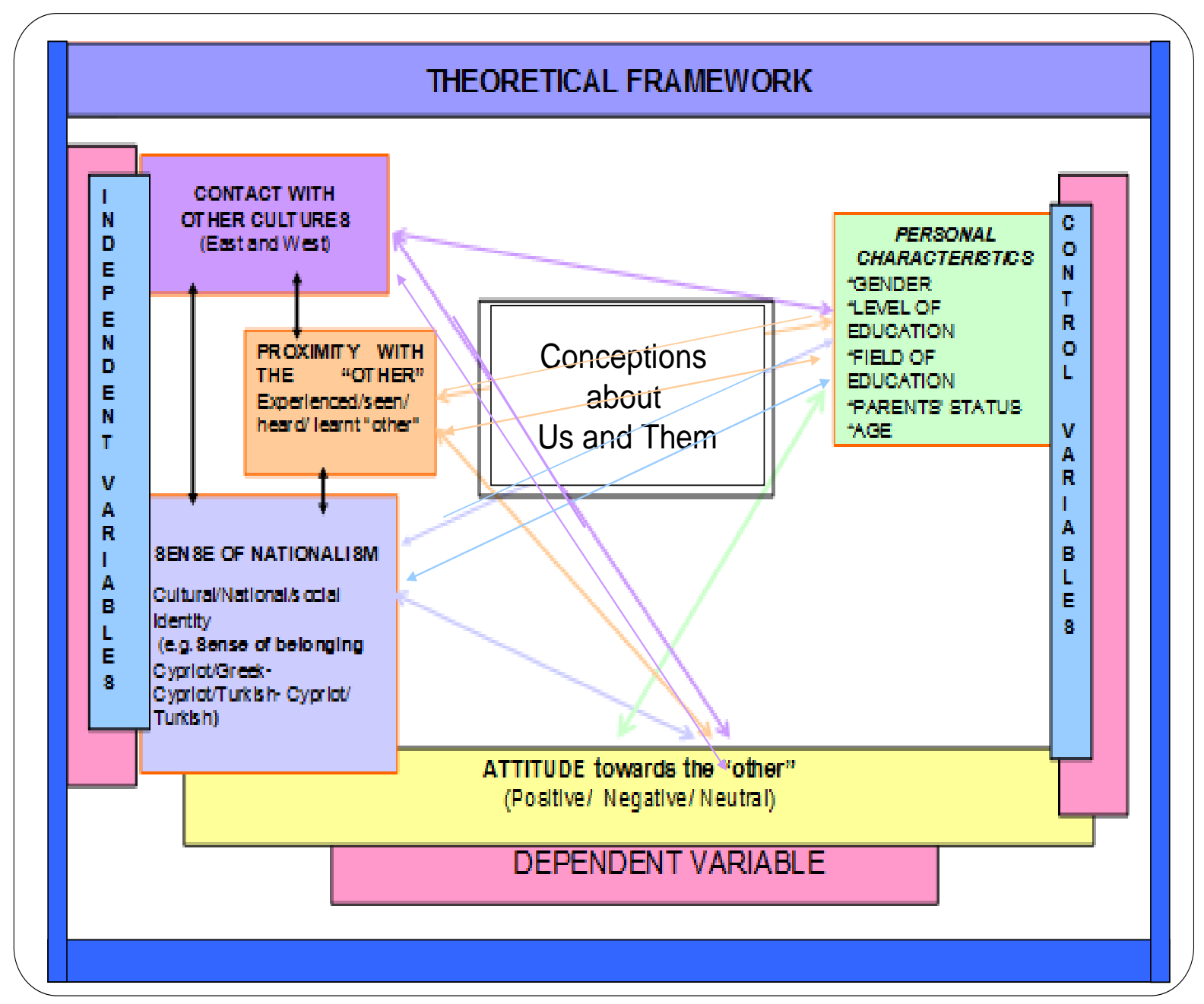

Figure 4. Thesis Theoretical framework 
Table 1. Nationality, gender and age of the students

\begin{tabular}{|c|c|c|c|c|c|c|c|c|}
\hline & \multicolumn{4}{|c|}{ Greek Cypriot } & \multicolumn{4}{c|}{ Turkish Cypriot } \\
\hline & \multicolumn{2}{|c|}{ Women } & \multicolumn{2}{c|}{ Men } & \multicolumn{2}{c|}{ Women } & \multicolumn{3}{c|}{ Men } \\
\hline Age & F & $\%$ & F & $\%$ & F & $\%$ & F & \% \\
\hline $17-20$ & 15 & $(31)$ & 8 & $(18)$ & 14 & $(31)$ & 17 & $(41)$ \\
\hline $21-24$ & 29 & $(61)$ & 27 & $(60)$ & 29 & $(63)$ & 25 & $(59)$ \\
\hline $25-28$ & 2 & $(4)$ & 8 & $(18)$ & 2 & $(4)$ & 0 & $(0)$ \\
\hline Above 28 & 2 & $(4)$ & 2 & $(4)$ & 1 & $(2)$ & 0 & $(0)$ \\
\hline Total & 48 & 100 & 45 & 100 & 46 & 100 & 42 & 100 \\
\hline
\end{tabular}

\subsection{Research Procedures}

A closed-typed questionnaire (for objective, precise and accurate answers) written in Greek and Turkish was prepared. The questionnaire was anonymous and easy to complete; the pre-test indicated that it took 15 minutes to complete. The questions referred to the goals of the study, and they were meaningful and interesting to respondents. Every word and phrase was used in a way that the questions would be clear and inoffensive. Experienced researchers evaluated the questionnaire, and its validity 7 was measured before the distribution.

The distribution of the questionnaires began in 2009 in four universities in the south of Nicosia (Greek Cypriots) and two universities in the north of Nicosia (Turkish Cypriots).

The categorization and analysis of the results was done using the SPSS statistical package. In order to find possible explanations of several results that came out from the quantitative analysis, the qualitative component of the research followed. Several studies have suggested that qualitative methods could follow quantitative methods [2-6]. The use of qualitative methods raises new questions and clarifications for a more holistic, deeper knowledge.

\subsection{Representativeness of Population Sample}

Greek and Turkish Cypriot university students pursuing undergraduate studies in Cyprus were the study population. The total number of Greek Cypriot students in 2007/08 was 10,305 , and the Turkish Cypriot university students' number was estimated 8 to be no more than 5,000. Therefore, a total number of 400 questionnaires were

7 Face validity refers to the extent to which a measuring instrument counts what it is supposed to count. The researcher randomly chose some Greek and Turkish Cypriot students who filled in a pre-test (questionnaire) and were then asked their opinion of the questions. Some questions were slightly altered for reasons of comprehension. It was noticed that some extra explanations should be given to the students for certain questions. For example, the terms refugee and immigrant were not very clear to all Cypriot students. Additionally, many students expressed their difficulty in filling in the last question on the questionnaire, which was posed on a semantic differential scale. Therefore, more specific instructions were given as the research took place [1].

8 There was a difficulty in finding the exact number of Turkish Cypriot university students, as access to statistical information was not possible, due to the existing political situation. distributed in order to get a sampling error of less than $2 \%$ [7]. Cypriot students, men and women from all fields of education participated in the research, in such a way that all sub-groups of undergraduate students were represented (Table 1).

\subsection{Quantitative Analysis Process}

The statistical analysis of the quantitative data was done using SPSS software. The reliability ${ }^{9}$ of the questionnaires was checked. Each questionnaire was accepted if the respondent was Cypriot and pursued undergraduate studies. Out of 400 distributed questionnaires, 181 were reliable: 93 valid for Greek Cypriots and 88 for Turkish Cypriots.

The questions were grouped in several ${ }^{10}$ categories that led to one of the variables in question (attitude, nationalism, proximity with the Other and contact with other cultures). Attitude was measured by questions ranked with the Likert and semantic differential scales, that dealt with like/dislike, agree/disagree, favourable/unfavourable, approve/disapprove statements. Proximity, nationalism and contact with other cultures were studied as independent variables, using the Likert and/or nominal scales. Other variables, such as gender, age, field/level of study and parents' status, were considered as control variables. These, were also assessed by questions using the nominal and Likert scales.

The second part of the questionnaire (Table 3) dealt with characterising 'themselves' in comparison with the Other Cypriot. Students were given a list of adjectives in a semantic differential scale and were asked to mark their level of agreement. In this way, Positive Me, Negative Me, Positive Other and Negative Other were formed.

As can be seen in Table 2, Cronbach's alpha test for

9 Reliability refers to the answers of each one of the samples. To check whether each person took the questionnaire seriously (and the answers were reliable), or whether the person just randomly circled the answers, two questions were repeated with slight alterations. For example, the question "I would like to have Turkish Cypriot friends"/ "I would like to have Greek Cypriot friends" was repeated twice in different parts of the questionnaire. Several incomplete questionnaires were also considered unreliable.

10 Cronbach's alpha was calculated for all variables. In this way, it indicated whether certain questions in the questionnaire explained the same variable, and consequently, could be considered as a variable. 
reliability showed that for all the variables there was an acceptable or high inter-item correlation.

Correlations between the controlled, dependent and independent variables were examined. Statistical techniques, such as frequencies, percentages, means, standard deviations, crosstabs, reliability statistics
(Cronbach's alpha), non-parametric correlations (Spearman $^{5}$ and independent samples t-tests were used in the analysis. In order to use the t-test, values above 40 were considered safe to use even if the data were heavily skewed.

Table 2. Cronbach's Alpha

\begin{tabular}{|c|c|}
\hline & Cronbach's Alpha Based on Standardised Items \\
\hline Attitude & 0.86 \\
\hline Contact with other cultures & 0.64 \\
\hline Proximity with the Other & 0.68 \\
\hline Sense of nationalism & 0.61 \\
\hline Positive Me & 0,73 \\
\hline Negative Me & 0,75 \\
\hline Negative Other & 0,78 \\
\hline Positive Other & 0,73 \\
\hline
\end{tabular}

Table 3. Semantic differential scale

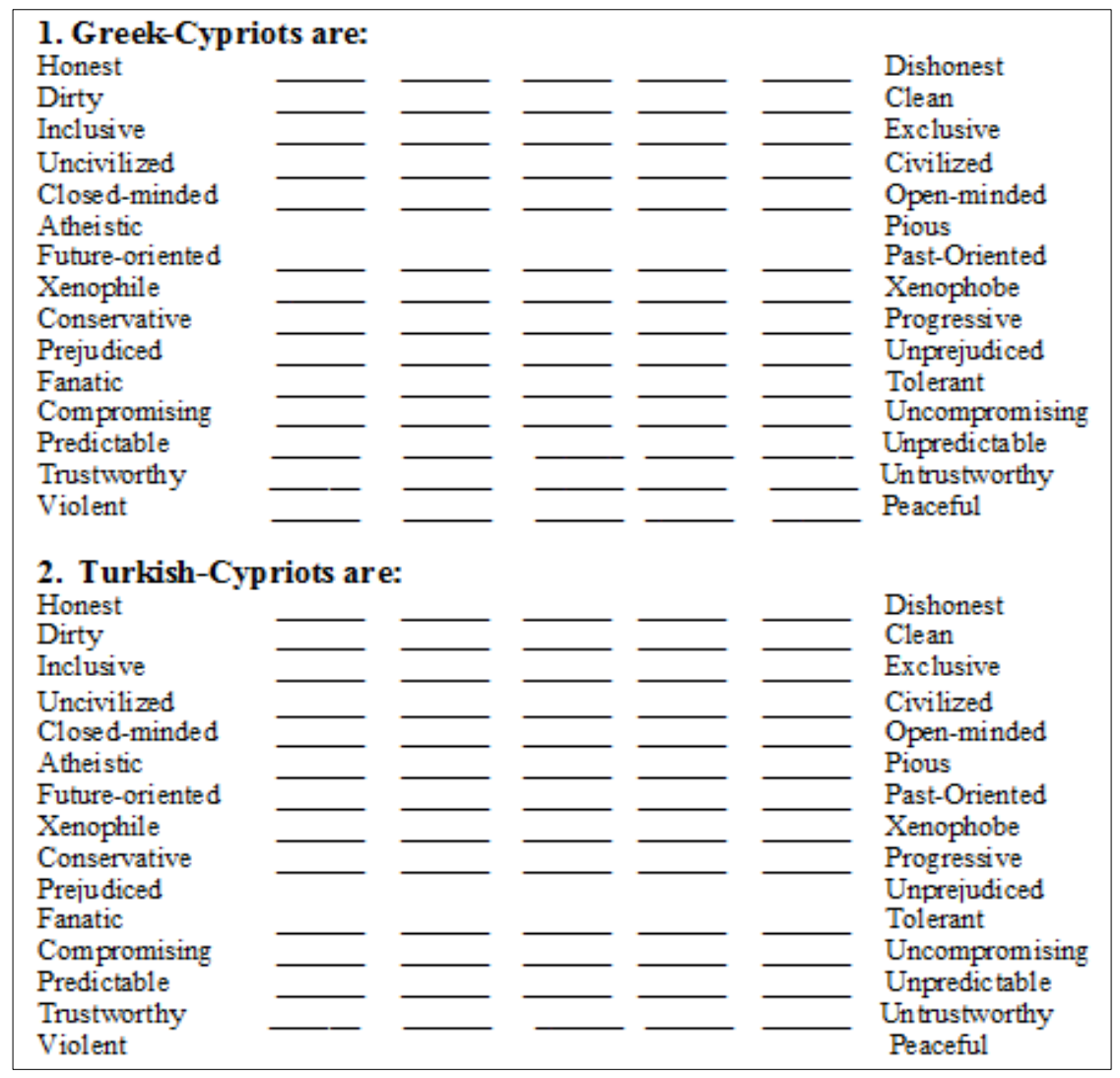


Table 4. Possible explanations and resources

\begin{tabular}{|c|c|c|c|}
\hline & ISSUES & Type of document (s) & How is analyzed in the study \\
\hline $\mathbf{l}$. & $\begin{array}{l}\text { Sense of } \\
\text { victimization } \\
\text { Victimization } \\
\text { expressed in } \\
\text { political/economical } \\
\text { and in educational } \\
\text { le vel }\end{array}$ & $\begin{array}{l}\text { 1. Real Photos (very often seen and used- } \\
\text { importance of symbols, G.C loss of human } \\
\text { lives, properties, dreams. } \\
\text { Poster (Greek Cypriots atte mpt to bring the } \\
\text { Other to their place) } \\
\text { 2. Written document (Turlish Cypriot } \\
\text { Pninisty-those who.... Poor and not } \\
\text { recognised T.C side) }\end{array}$ & $\begin{array}{l}\text { 1. Photo analysis worksheet } \\
\text { (Dacument 1) }\end{array}$ \\
\hline 2. & $\begin{array}{l}\text { Distinction of } \\
\text { special id entities } \\
\text { Turtish citizens and } \\
\text { Turhish Cypriots } \\
\text { Immigrants }\end{array}$ & $\begin{array}{l}\text { 1. Written document (newspaper articles)' } \\
\text { Turhish Cypriots de monstrations } \\
\text { (28 January } 2011 / 2 \text { March 2011)-photos, } \\
\text { media coverage }\end{array}$ & $\begin{array}{l}\text { 1. Docum ent analysis worksheet } \\
\text { (Document 3) }\end{array}$ \\
\hline
\end{tabular}

\subsection{Qualitative Analysis Process}

The use of qualitative methods that followed the quantitative ones set limits to several explanations, raised new questions and gave new explanations in order to gain more holistic and deeper knowledge. For example, the statistical analysis showed several correlations related to the attitudes of Greek and Turkish Cypriot university students towards each other, related to their attitudes towards 'their' group and the 'other' group. However, the researcher needed to find further explanations for different correlations. Qualitative methods gave the opportunity to the researcher to study things from another point of view and to justify correlations. At this point the new hypotheses (see Materials and Methods) of the research were formed and additional information was gathered with the use of qualitative data. Documentary analysis was chosen instead of other qualitative methods. Interviews could not happen because of language obstacles (the researcher did not speak Turkish). In addition, the Greek Cypriot identity of the researcher could have affected the responses. Table 4 presents a catalogue of possible subjects or possible explanations and resources that the researcher prepared for the purposes of the qualitative analysis.

"Sense of Victimization" and "Distinction of Special Identities" were the two subjects that were studied by qualitative research. The author [1] gathered several photos and written documents (that were very often seen and used by Greek and Turkish Cypriots), and developed new hypotheses. Based on Tally [7]'s ideas ${ }^{11}$, for the analysis of

11 Tally [8] suggested that analysis should be done on three levels: observation (exact description of what we see in the photo), knowledge (summary of what we know about the situation, the time-period, the the photographs, the researcher created two photo analysis worksheets (Table 5 and Table 6), one for the Greek Cypriots' point of view, and one for the Turkish Cypriots' point of view [8]. There followed the observation and discussion of several patterns. The researcher prepared two further document analysis worksheets for the documentary analysis. The documentary analysis dealt with questions such as "How are the documents written? How are they read? Who writes them? On what occasion? What is the outcome? What does the writer take for granted? The answers to the above questions were related to the pre-existing set of categories that emerged from the quantitative research.. people and the objects), and interpretation (the conclusion from what we see). Additionally, the National Archives 11 photo analysis worksheet suggested that we study the photo for two minutes and then write about the people, objects and activities. 
Table 5. Greek Cypriot students’ perspective

\begin{tabular}{|c|c|c|c|c|}
\hline \multicolumn{5}{|c|}{ Photo Analvsis Worksheet } \\
\hline \multicolumn{5}{|c|}{ A. Studying and dividing the photos into people, objects and activities } \\
\hline & People & Objects & Activities & Messages \\
\hline Picture 1 & A child & $\begin{array}{l}\text { The child's } \\
\text { parents' } \\
\text { wedding photo }\end{array}$ & $\begin{array}{l}\text { - The child is holding } \\
\text { the photo. He lost his } \\
\text { parents in } 1974 . \\
\text { - A woman is } \\
\text { demonstrating in the } \\
\text { background }\end{array}$ & $\begin{array}{l}\text { - The inhumane } \\
\text { side of the Turks/ } \\
\text { Turkish Cypriots } \\
\text { in 1974 } \\
\text { - Women and } \\
\text { children as } \\
\text { victims }\end{array}$ \\
\hline Picture 2 & Women & $\begin{array}{l}\text { Photos } \\
\text { missing } \\
\text { persons }\end{array}$ & $\begin{array}{l}\text { Women } \quad \text { (mothers/ } \\
\text { sisters) are } \\
\text { demonstrating, asking } \\
\text { for justice, enquiring } \\
\text { about their loved ones }\end{array}$ & $\begin{array}{l}\text { - The pain } \\
\text { of the mother } \\
\text { who loses her } \\
\text { child } \\
\text { (e.g., People } \\
\text { should lourists) } \\
\text { and help the GC } \\
\text { cause by not } \\
\text { supporting the } \\
\text { inhumane } \\
\text { enemy }\end{array}$ \\
\hline Picture 3 & $\begin{array}{l}\text { Men/ } \\
\text { prisoners }\end{array}$ & $\begin{array}{l}\text { Navy cargo } \\
\text { ship (violent } \\
\text { transfer) }\end{array}$ & $\begin{array}{l}\text { - Male prisoners are } \\
\text { unable to react, they } \\
\text { are tied... They cannot } \\
\text { see, walk, touch, talk... }\end{array}$ & $\begin{array}{l}\text { - Lack of } \\
\text { respect for human } \\
\text { rights from Turks } \\
\text { and Turkish } \\
\text { Cypriots }\end{array}$ \\
\hline Picture 4 & Men killed & $\begin{array}{l}\text { Legs of other } \\
\text { people (there } \\
\text { are witnesses) }\end{array}$ & - No action & $\begin{array}{l}\text { No respect } \\
\text { for human life }\end{array}$ \\
\hline Picture 5 & 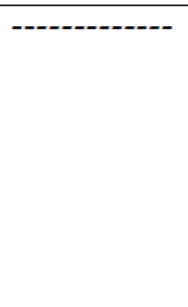 & $\begin{array}{l}\text { • Map of } \\
\text { U.S.A. } \\
\text { - Map } \\
\text { of Cyprus }\end{array}$ & $\begin{array}{l}\text { - Imaginary } \\
\text { division/occupation of } \\
\text { U.S.A. } \\
\text { - Real division of } \\
\text { Cyprus }\end{array}$ & $\begin{array}{l}\text { "Other countries } \\
\text { should empathise } \\
\text { with the pain and } \\
\text { unfair treatment } \\
\text { of Greek Cypriots } \\
\text { by the } \\
\text { Turkish/Turkish } \\
\text { Cypriots" }\end{array}$ \\
\hline \multicolumn{5}{|c|}{$\begin{array}{l}\text { B. List of common messages } \\
\text { Greek Cypriots, especially women and children, are the real victims of the conflict. } \\
\text { The inhumane side of the 'Other', where the 'Other' is synonymous with "those who } \\
\text { killed, who orphaned children and rendered women unprotected". }\end{array}$} \\
\hline
\end{tabular}


Table 6. Photo Analysis Worksheet

\section{Photo Analvsis Worksheet}

A. Studying and dividing the photos into people, objects and activities

\begin{tabular}{|c|c|c|c|c|}
\hline & People & Objects & Activities & Messages \\
\hline Picture 1 & $\begin{array}{l}\text { Women and } \\
\text { children }\end{array}$ & $\begin{array}{l}\text { In their } \\
\text { village } \\
\text { square }\end{array}$ & Crying, wondering why & $\begin{array}{l}\text { - The inhumane } \\
\text { side of the } \\
\text { Greek/Greek } \\
\text { Cypriots in } 1964 \\
\text { - Women and } \\
\text { children as } \\
\text { victims }\end{array}$ \\
\hline Picture 2 & $\begin{array}{l}\text { Elder } \\
\text { Turkish } \\
\text { Cypriot, } \\
\text { soldiers, } \\
\text { civilians }\end{array}$ & $\begin{array}{l}\text { Dead bodies- } \\
\text { mass grave } \\
\text { Many } \\
\text { witnesses }\end{array}$ & $\ldots$ & $\begin{array}{l}\text { Lack of respect } \\
\text { for human life } \\
\text { from Greek } \\
\text { Cypriots, } 1974\end{array}$ \\
\hline Picture 3 & $\begin{array}{l}\text { Murdered } \\
\text { children }\end{array}$ & bathroom & $\ldots$ & $\begin{array}{l}\text { - Lack of } \\
\text { respect for human } \\
\text { life by Greek } \\
\text { Cypriots, } 1963\end{array}$ \\
\hline Picture 4 & $\begin{array}{l}\text { Murdered } \\
\text { men }\end{array}$ & $\begin{array}{l}\text { On the } \\
\text { ground }\end{array}$ & $\ldots$. & $\begin{array}{l}\text { - Lack of } \\
\text { respect for human } \\
\text { life from Greek } \\
\text { Cypriots, } 1964\end{array}$ \\
\hline
\end{tabular}

\section{B. List of common messages}

Turkish Cypriots, especially women and children are the real victims of the conflict.

The inhumane side of the 'Other', where 'Other' is synonymous with "those who killed, who orphaned children and rendered women unprotected".

Table 7. Correlations between measures (A)

\begin{tabular}{|c|c|c|c|c|c|c|c|c|c|}
\hline & & Gender & Age & Field & Parents & Contact & Proximity & $\begin{array}{l}\text { Sense } \\
\text { national ism }\end{array}$ & of Attitude \\
\hline Gender & & 1.00 & 0.046 & -0.15 & -0.055 & -0.043 & -0.133 & -0.056 & 0.063 \\
\hline Age & & & 1.00 & -0.191 & -0.081 & 0.039 & 0.043 & 0.182 & 0.126 \\
\hline Field & & & & 1.00 & 0.018 & 0.017 & 0.051 & -0.053 & -0.196 \\
\hline Parents & & & & & 1.00 & 0.062 & 0.013 & -0.097 & -0.036 \\
\hline Contact & & & & & & 1.00 & $0.465^{* *}$ & 0.052 & $0.406 *$ \\
\hline Proximity & & & & & & & 1.00 & 0.182 & $0.453^{* *}$ \\
\hline $\begin{array}{l}\text { Sense } \\
\text { nationalism }\end{array}$ & of & & & & & & & 1.00 & $0.480^{* *}$ \\
\hline Attitude & & & & & & & & & 1.00 \\
\hline
\end{tabular}




\subsection{Ethical Questions}

This research paid special attention to several moral and ethical issues that the author overcame with the use of mixed research methods. The research discussed complies with four agreed international standards: Beneficence, Non-malfeasance, Informed consent, and Confidentiality/Anonymity, as suggested by the Declaration of Helsinki. The participants were fully protected: their responses were anonymous, there was no pressure on them to participate, they could withdraw from the research at any time and they were fully informed in their mother tongue about the purposes of the research by a cover letter.

One could argue that this research participates in producing or reproducing banal nationalism (as described by Billig, 1995), as it deals with describing the attitude of groups of people. However, the research in discussion described and informed and could not really produce banal nationalism, as the dividing line between Greek and Turkish Cypriots does exist, both physically and morally [10].

A methodological challenge of the researcher, due to her Greek Cypriot identity, was the issue of recognition. Since 1982, when the Turkish Cypriots established the so-called Turkish Republic of Northern Cyprus (TRNC), there has been an enormous effort from the Greek Cypriot side to deny the 'illegal state', which is not recognised internationally. The researcher was asked informally during friendly discussions about 'recognising' the TRNC by visiting their universities in the 'Turkish-occupied area' (as it is called by Greek Cypriots) in order to conduct research. However, the researcher, in reference to other studies (e.g. [11]) and international laws, supports the view that in cases of educational and social research the issue of recognition should not exist.

In order to be as objective as possible, the researcher used (in the questionnaire) specific words that could be politically construed, based on European and world decisions on the Cypriot issue (e.g. Turkish invasion vs. Turkish interference, border vs. dividing line/line, government vs. authority, settlers vs. immigrants, majority/minority vs. community).

Another ethical issue was the language limitation, as the researcher did not speak Turkish. This was solved by the decision to use a closed-type questionnaire. In terms of communication with Turkish Cypriots, this was an easy task, as the majority of the participants were competent in English. In order to solve possible language problems with Turkish Cypriot students, and when English could not be used, the researcher was escorted by a Turkish Cypriot student who acted as a translator. The researcher used varied sources (Greek Cypriot, Turkish Cypriot, non-Cypriot, non-Greek and non-Turkish authors) in all parts of the research.

Indisputably, the decision to use mixed methods enabled the researcher to deal with important ethical questions.

\section{Results}

The first part of this research revealed statistically significant correlations (Table 7). For example, the attitude of the students towards the other and their proximity (contact) with the Other were positively correlated (see also [12-17]).

An important finding was that despite the students' eagerness to participate in more programmes to meet the Other, participation levels remained very low. Attitudes towards the Other and a sense of nationalism were positively correlated. The Greek Cypriot and Turkish Cypriot participants tried to maintain a positive distinctiveness of their in-groups over their out-groups. However, the qualitative research showed that Turkish Cypriots appeared less negative towards their out-group compared with Greek Cypriots. Furthermore, the research showed that mainly Greek Cypriots were concerned about language and religion. In addition, the study showed that respondents from both sides studied history monolithically, which means that they learnt history written by writers from their in-group.

Furthermore, attitudes towards the Other and contact with other cultures were positively correlated, and we note similarities with Sharma and Jung [18], several European decisions, Gudykunst [19] and Tannen [20], and others.

Interestingly, Turkish Cypriots appeared more eager to meet other cultures (East and West); they had heard about, read about and lived in other cultures more than Greek Cypriot participants had. In addition, the Turkish Cypriot students did not wish to have stronger ties with Turkey in the future. These two findings raised new questions that were further analysed with the use of qualitative research methods.

The new questions were as follows:

1 Why did Turkish Cypriots not want to have closer ties with Turkey?

2 Is this result supported by other evidence?

3 What is the relationship between Turkish Cypriots and Turks living in Cyprus?

4 How do Greek Cypriots perceive Turkish Cypriots?

5 Could all these relate to the rather negative attitude of Greek Cypriots towards the other and other cultures?

Using qualitative research methods at this point of the study enabled us to give possible explanations as to why things happen. The results of the documentary analysis showed, on the one hand, the attempt by Turkish Cypriots to become more independent from Turkey and distinguish themselves from Turks living in Cyprus. On the other hand, the results showed that Greek Cypriots considered Turks and Turkish Cypriots as one group and connected them to

Turkey, which they saw as an invader. This finding could partly explain the more negative attitude of Greek Cypriot students towards Turkish Cypriots.

Lastly, one of the quantitative analysis findings was that Turkish Cypriot participants had a more positive attitude 
towards their in-group (Turkish Cypriots) and towards their out-group (Greek Cypriots). However, Greek Cypriots maintained a more negative attitude towards the Other. Additionally, Greek Cypriot participants largely supported the view that their in-group was seen as the victim of the Turkish invasion of 1974. In reference to this observation, it could be assumed that Greek Cypriots felt a stronger sense of victimisation than the Turkish Cypriots. At this point the researcher employed qualitative research to examine the above assumption. The qualitative research results sent strong messages of unfair treatment coming from both sides, expressed through photographs and document circulation. Therefore, the assumption that Greek Cypriot students' more negative attitude towards the Other could be explained as a consequence of their stronger sense of victimisation had limited validity. The use of qualitative research in this case placed limitations on the explanations of quantitative research. The results are summarised and presented in Table 8.

The discussion that follows aims to make explicit the contribution to knowledge of mixed methods in sociological research.

Table 8. Summary of the research

\begin{tabular}{|c|c|c|c|c|}
\hline & ATTITUDE & Conception of us & Conception of them & Cyprus issue \\
\hline $\begin{array}{l}\text { Turkish } \\
\text { Cypriots }\end{array}$ & $\begin{array}{l}\text { - More contact with } \\
\text { other cultures, } \\
\text { except the Cypri ot } \\
\text { one } \\
\text { - More proximity } \\
\text { with the "Other' } \\
\text { - Less } \\
\text { nationalistic } \\
\text { attitude } \\
\text { positive attitude } \\
\text { towards Greek } \\
\text { Cypriots } \\
\text { - Peaceful } \\
\text { co-existence } \\
\text { possible. } \\
\text { - More negative in } \\
\text { relation to family } \\
\text { and close relations }\end{array}$ & $\begin{array}{l}\text { - Emphasis on } \\
\text { Cypriotness } \\
\text { - Economically } \\
\text { advantaged } \\
\text { - Greek Cypriots are } \\
\text { more honest, inclusive, } \\
\text { atheistic, future } \\
\text { oriented, xenophile, } \\
\text { compromising, } \\
\text { predictable and } \\
\text { trustworthy compared to } \\
\text { 'them' } \\
\text { - More negative in } \\
\text { describing 'us" } \\
\text { compared to Turkish } \\
\text { Cypriots } \\
\text { - Victims of } 1974, \\
\text { correlated with } \\
\text { attitude towards the } \\
\text { 'Other' and to sense of } \\
\text { nationalism } \\
\text { - Majority (cultural } \\
\text { threats: } \\
\text { language/religion, } \\
\text { preservation of } \\
\text { economic status) } \\
\text { - Emphasis on } \\
\text { Cypriotness } \\
\text { - Less economically } \\
\text { advantaged than 'them' } \\
\text { - Turkish Cypriots are } \\
\text { more honest, inclusive, } \\
\text { atheistic, future } \\
\text { oriented, xenophile, } \\
\text { compromising, } \\
\text { predictable and } \\
\text { trustworthy, compared } \\
\text { to "them" } \\
\end{array}$ & $\begin{array}{l}\text { - Economically } \\
\text { disadvantaged } \\
\text { - Turkish Cypriots } \\
\text { are more dirty, } \\
\text { uncivilised, closed } \\
\text { minded, } \\
\text { conservative, } \\
\text { prejudiced, fanatical } \\
\text { and violent } \\
\text { compared to 'us' } \\
\text { - More negative in } \\
\text { describing 'them" } \\
\text { compared to Turkish } \\
\text { Cypriots } \\
\text { - Turkish Cypriots } \\
\text { support Turkish } \\
\text { policies in Cyprus } \\
\text { - Non-distinction } \\
\text { of special identities } \\
\text { (Turkish/Turkish } \\
\text { Cypriots)? } \\
\text { - Functional } \\
\text { minority } \\
\text { - More economically } \\
\text { advantaged than 'us" } \\
\text { more dirty, } \\
\text { mincivilised, closed } \\
\text { conservative, } \\
\text { prejudiced, fanatical } \\
\text { and violent } \\
\text { compared to "us' } \\
\end{array}$ & $\begin{array}{l}\text { - } \\
\text { Inter-communal } \\
\text { problem } \\
\text { lack of respect for } \\
\text { human rights } \\
\text { 1974 friendly } \\
\text { interference from } \\
\text { Turkey } \\
\text { Loss of } \\
\text { property=sacrifice } \\
\text { for self- } \\
\text { governance } \\
\text { Non-recognised } \\
\text { state } \\
\text { Turkish military = } \\
\text { threat or } \\
\text { protection } \\
\text { - }\end{array}$ \\
\hline
\end{tabular}




\section{Discussion}

It is the philosophy of this research that qualitative and quantitative research methods are not mutually exclusive, but they can interact to produce knowledge (see also Newman and Benz [21]). It is necessary to make new research combinations and experiment according to the knowledge we want to produce. Similar ideas were expressed by Miles and Huberman ${ }^{12}$ [5], who suggested that each approach could help out the other at the stages of design (e.g. to find the representative sample) and data analysis (e.g. generality of observations, verifications and casting new light on existing findings.

The combination of the two methods in this research provided an insight into the attitudes of Greek and Turkish Cypriot university students. The qualitative research was more suitable for studying the structural features of social life, whereas the strengths of quantitative methods lay in its process aspects. Put simply, the quantitative research was quite good at telling us what was happening, whereas the qualitative studies were better at determining why events occured. Arguably, mixed methods were more suitable for this study, because the researcher aimed at descriptions of 'what' and 'why'. Qualitative research facilitated researching the relationships between variables, and quantitative research gave explanations of possible relationships. Because of the use of quantitative methods, a greater number of students participated. Therefore, the results could be generalised. From the quantitative approaches, new questions arose that required further analysis using qualitative methods. The involvement of the researcher needed to be eliminated during the fieldwork, which was achieved with the use of the closed-type questionnaire. The closed-type questionnaire was also necessary due to the language limitations.

\section{Conclusions}

This research aimed to explore the attitudes of Greek and Turkish Cypriot university students. It revealed 'us and them' conceptions and aspects of the students' societal context. The combination of quantitative and qualitative research methods led to important results. The qualitative research methods (analysis of various documents such as photos and newspaper articles) that followed the quantitative approach (SPSS, statistical analysis) facilitated the further analysis of the results and set limitations on the explanations. One of the findings of the quantitative research was that students from both sides expressed "feelings of unfair treatment from the 'Other' side". The qualitative research that followed showed how and why a sense of victimisation could relate to students' attitudes. Another example is that the quantitative research showed that Greek Cypriots had a more negative attitude towards the 'Other' compared to Turkish Cypriots. The qualitative research aimed to further explain this result, and it showed that while Turkish Cypriots tried to differentiate themselves from the settlers from Turkey, Greek Cypriots did not recognise the difference between the two groups. This conclusion could explain better the more negative attitude of Greek Cypriots towards Turkish Cypriots

The example of this successful mixed-methods research could be used as a methodological example for other studies, in other culturally diverse environments that face similar challenges with the case of Cyprus.

\section{Biographical Notes on the Contributor}

Andri Neophytou was born in Cyprus in 1982. She graduated with a BS in Educational Sciences from the University of Cyprus in 2004, and has an MSc in Cultural Diversity and a PhD in Sociology from the University of Eastern Finland, with research and professional experience in the sociology of education and intercultural education. Her master's thesis, published by the University of Joensuu in 2005, dealt with the teaching of social courses (religious education) in Cypriot primary schools. She used qualitative analysis methods to examine the curriculum, schoolbooks and teaching practices in religion classes. More specifically, her master's thesis examined the religious education curriculum and the content of the proposed schoolbooks in primary schools to see if they were interconnected and if together they promoted understanding, fairness and equality. It was a unique work, according to the Finnish evaluators of her research (Teuvo Laitila and M'hammed Sabour). In 2014, the University of Eastern Finland published her $\mathrm{PhD}$ thesis in sociology. Supervised by Professor Sabour, this dealt with the attitudes of Greek and Turkish Cypriot university students towards the 'Other'. It used a combination of qualitative and quantitative research methods, and it was evaluated with the second highest grade in the Finnish grading scale. In writing her thesis, she worked with theories concerning the construction/deconstruction of attitudes, nationalism, image of the 'Other' or the enemy, peace education, conflict resolution, stereotypes and minority/majority issues. In addition to the Cypriot issue, she investigated several other examples of protracted conflict societies (e.g. Israel/Palestine and others) in her $\mathrm{PhD}$ studies.

She has written scholarly articles and presented her research at academic conferences. For the last 13 years she has worked as an educator in Greek Cypriot primary schools. Additionally, she has participated and/or organised local, European and bi-communal (for Greek and Turkish Cypriots) projects (Jumpstart, YE.U (Youth for exchange and Understanding)., Salto Youth, Home, University of Cyprus and the Teachers' Union). 


\section{REFERENCES}

[1] A. Neophytou. Conceptions of 'Us' and 'Them': The Attitude of Greek Cypriot and Turkish Cypriot University Students towards the 'Other', University of Eastern Finland Press, Joensuu, 2014.

[2] T. Black. Doing quantitative research in the social sciences: An integrated approach to research design, measurement and statistics, London, Sage Publications, 1999.

[3] T. Black. Understanding social science research (2nd ed.), University of Eastern Finland, Sage Research Methods Online, 2002.

[4] A. Bryman. Quantity and quality in social research. London, Unwin and Hyman, 1988.

[5] M. Miles, M.Huberman, Qualitative data analysis, Sage publications, 1994.

[6] I. Newman, C. Ben. Qualitative-quantitative research methodology: Exploring the interactive continuum, Chigago, Southern Illinois University, 1998.

[7] K. Papanastasiou. Methodology of educational research. Nicosia, University of Cyprus, 1996.

[8] B. Tally. Photo analysis guide, Retrieved from http://www.cyberbee.com/quicklessons/photo.html, 1997.

[9] K. Punch. Introduction to social research: Qualitative and quantitative approaches, Sage Publications, 1998.

[10] E. Said. Orientalism, New York: Vintage Books, 1978.

[11] C. Constantinou \& Y. Papadakis. The Cypriot state(s) in situ: Cross ethnic contact and the discourse of recognition, Global Society 15(2), 125-148, 2001.

[12] F. O. Hampson Nurturing peace: Why peace settlements succeed or fail, Washington, DC, United States Institute of Peace Press, 1996.

[13] J.P. Lederach. Building peace: sustainable reconciliation in divided societies, Washington, DC: United States Institute of Peace Press, 1997.

[14] D. J. Lønning. Israeli ways of conceptualising the enemy, and implications for Israeli - Palestinian grass-roots dialogue, In M. Sabour \& K. S. Vikor (Eds.), Ethnic encounter and culture change, (pp. 36-48), Bergen: Nordic Society for Middle Eastern Studies, 1997.

[15] I Maoz. An experiment in peace: reconciliation-aimed workshops of Jewish-Israeli and Palestinian youth, Journal of Peace Research November, 37(1/2) 721-736, 2000.

[16] T.F. Pettigrew. Intergroup contact theory, Annual Review of Psychology 49, 65-85, 1998.

[17] S.C.Wright, A. Aron, T.McLaughlin, A.S. Ropp. The extended contact effect: knowledge of cross-group friendships and prejudice, Journal of Personality and Social Psychology 73(1), 73-90, 1997.

[18] M. Sharma, L. Jung. How cross-cultural social participation affects the international attitudes of U.S. students,
International Journal of Intercultural, Relations, 9(4), 377-387, 1985.

[19] W. Gudykuns. Bridging Differences. Effective intergroup communication, (3rd ed.), New York, Sage Publications. 1998.

[20] D. Tannen. Framing in discourse, New York, Oxford University Press, Georgetown University 1993,

[21] I. Newman, C. Benz. Qualitative-quantitative research methodology: exploring the interactive continuum, Chigago, Southern Illinois University, 1998.

[22] R.K. Monroe, J. Hankin, \& V. Vechten. The psychological foundations of identity politics. Annual Review of Political Science, 3, 419-447, 2000.

[23] Z. Bauman \& T. May. Thinking sociologically (2nd ed.) Oxford, Blackwell Publishers, 2001.

[24] N. Papastergiadis. Tracing Hybridity in Theory. In P. Werbner., \& T. Modood. (Eds.), Debating Cultural Hybridity: Multi Cultural Identities and the politics of Anti-Racism, 257-281, 1997.

[25] E. Said. Orientalism. New York, Vintage Books, 1978.

[26] W. Gudykunst. Bridging Differences. Effective intergroup communication. New York, Sage Publications,1998 